\title{
Taking Action against Anti-Healthcare Violence in China
}

Zhiyi Zhang, Weiyan Wang and Yue Zhang*

First Clinical College, Harbin Medical University, China

*Corresponding author: Yue Zhang, First Clinical College, Harbin Medical University, Harbin 150001, China, Tel: 864518666 6421; E-mail: toronto101@163.com

Received date: September 16, 2016; Accepted date: September 20, 2016; Published date: September 23, 2016

Copyright: (c) 2016 Zhang Z, et al. This is an open-access article distributed under the terms of the Creative Commons Attribution License, which permits unrestricted use, distribution, and reproduction in any medium, provided the original author and source are credited.

\section{Editorial}

Medical doctors and nurses are the key endpoints of delivery for our service of medicine and therapy. However, similar to gun violence in the US [1], the virulent anti-healthcare violence $(\mathrm{AHcV})$ has rampaged like a type of "virus" in China for a while and is a public healthcare problem worldwide as well. Fortunately, although we lagged behind other countries during the last century, China would now like to catch up with their counterparts in innovation and leadership in many aspects. On August 20, 2016 President Xi, Jin-Ping initiated an action against $\mathrm{AHcV}$ in the State Council Congress of China Central Government [2] in that the $\mathrm{AHcV}$ is contrary to the health of the people. Like or even better than the US in some aspects, we stand with our relatives, friends, colleagues and patients, and we also learn from the resilience of our community, which has demonstrated the power of a fast-responding and well-organized humanitarian movement to transform our society, our laws and our culture [1]. Hopefully, actions against the $\mathrm{AHcV}$ in China will become exemplary in the near future.

We, as a medical community, could have a unique voice against $\mathrm{AHcV}$. Medical doctors and nurses are on the frontlines of the response to AHcV. On May 5, 2016, the director of the oral health division in a hospital in South China was fatally stabbed by a patient he had treated 25 years previously. Two days later, another doctor in West China was brutally stabbed. Following the 2012 murder of Wang Hao in our department in Northeast China, an online poll revealed that the majority $(65 \%)$ was pleased about it but only $6.5 \%$ felt sorrow. These tragedies highlight that medical treatment problems account for $<28 \%$ of patient-physician conflicts in China. In the wreckage of the destroyed lives and health of medical doctors and a traumatized community left behind by such murders and violence, the Chinese seem to be perplexed about what kind of issue this is and why it exists. Is it a hate trend against the medical community? How do we solve this? Again and again, many healthcare workers have poured into the streets and crowded around hospitals to give respect to their deceased colleagues and give themselves the hope of fighting $\mathrm{AHcV}$. Sometimes they feel lonely and hopeless. Such violence demands us to take responsibility and commit ourselves to engaging in action against $\mathrm{AHcV}[1]$.

$\mathrm{AHcV}$ in China is a complicated problem, like gun violence in US. $\mathrm{AHcV}$ comes in at least four types: direct assaults on medical doctors, aggression against nurses, accidental attacks that accompany with mental diseases and "yi-nao" (irrational demands for remorse and remuneration from healthcare workers). Resolving any of these easily is not realistic [1].

However, the devastation of $\mathrm{AHcV}$ is not inevitable. However, considering that this kind of violence alone justifies the price of relatively high incomes for healthcare workers is a perversion of the notion of fairness toward those who are hard workers and deserve their rewards [1]. Although these four types of violence have varied root causes, they are unified by the mentality created by misleading information, failure to view doctoring as a true profession and Chinese philosophy all cause patient-physician mistrust.

Many actions may be taken to address the problem of $\mathrm{AHcV}$.

First, the media must be forbidden to misrepresent the medical profession. Previously, some patients initiated violence or yi-nao actions [3] and media contact. One typical yi-nao case happened in Harbin. The son of a deceased cancer patient used his influence to make contact with the media. Many Chinese reporters have little knowledge of medicine but inflame medical disputes for publicity. Our legal system has limited or no well-defined responsibility or ability to punish misrepresentation of such medical cases so we can gradually draw a line between reporters who do or do not act this way. Like in the West, medical doctors could take out operation insurance. According to new laws and regulations, police may take a zerotolerance attitude to $\mathrm{AHcV}$. Healthcare facilities need rapid-response systems including "WeChat" or covert codes (e.g. red meaning "fire", white meaning "violence' so the workers will understand the threat without causing panic among the patients, as in the University Health Network) and healthcare providers should receive self-defense training. Even as a last resort, healthcare workers could be taught the skills to negotiate with potentially violent individuals. We must equip up ourselves with strong and healthy bodies, which will also highlight the benefits of good exercise and sport medicine for both healthcare workers and patients. We must improve our own morality and ethical education, and our familiarity with safety. Policymakers could also create a national day against $\mathrm{AHcV}$.

Second, doctors' salaries should reflect their performance. Many patients perceive healthcare to have been commercialized with the introduction of capitalism. However, some young doctors intend to earn a high salary [4]. One academic in Chinese Academy of Sciences even proposed that doctors' salaries should be 3-5 times the average salary in society. In addition, most Chinese believe that doctors' incomes are not their salary alone. Furthermore, the Chinese medical community collectively is relatively unoriginal, meaning that imported drugs and apparatus remain expensive. Indeed, about 50,000 osteoarthritis-related articles appeared in CNKI but around 1,500 of them appeared in relatively better publications in PubMed. Now China's precision medicine system has been launched. We expect that innovations and originality in medicine should increase soon. The healthcare system should be patient-centered but should prioritize physician quality. The specialist standardization training system [5] may help improve the quality of newly-graduated doctors. A tiered medical system may provide patients with quality services. On the whole, we should nurture the profession of physicians.

Hospitals started to have zero-tolerance of bribes, favors and other in-kind benefits. Paradoxically, Chinese culture values "saving face" so that many things are non-transparent. Supposedly, alongside residual 
Page 2 of 2

"communism", our society prizes equality. In reality, incomes vary significantly, partly from differing levels of resource availability. Many gifts or favors could go as "modified" (hidden) bribes to recipients in a monopoly. Subsequently, social-economic pressure may impose mental and emotional threats to people that need psychologists. Being the target of bigotry, hatred and violence is not new for Chinese healthcare workers. Therefore, we could screen out potential hidden $\mathrm{AHcV}$ and conflicts with a vigorous anti-corruption movement.

Third, having well-kept transferrable records and biomedical research databanks of patients' details could benefit precision medicine6 and would aid in conflict resolution.

Huangzhou City initiated an X-ray security and safety detection system in its healthcare systems because China is to host the 2016 Group of Twenty (G20) summit in Hangzhou, one of most beautiful, safe and clean cities in China, best known for its scenic West Lake. This $\mathrm{X}$-ray system exposed seven officially-controlled potential assault weapons such as knives in one hospital during the first day of its pilot trial. Basically, this system is similar to those in airports and subway security control systems. Importantly, this should be expanded to other cities rather than fading away after the G20 summit. Although we laud their efforts, it would be far better if such systems could be deployed for most if not all healthcare facilities and we may be able to prevent $\mathrm{AHcV}$ from occurring in the first place. The ban on assault weapons should also be renewed. Without weapons, hate-filled individuals and those with mixed motivations will be prevented from doing extensive violence (Extra comment: X-rays are harmful to unborn babies so there could be some serious problems with X-ray systems scanning everyone coming into a hospital, so many patients, esp. pregnant women should have been given special concerns).

What could preclude X-ray installation in other medical centers in China? The cost? Given the, Chinese emphasis on "saving face", how do we protect patient privacy and should we report mental health histories that suggest a high risk of violence? But there is no excuse for stopping action. We need identify patients, their relatives or others who are at risk for any impulse towards violence. Moreover, we need further better assessment tools and pathways to provide education and resources for our at-risk patients [1].

Fifth, China is revolutionizing the pricing systems of apparatus and pharmaceuticals in healthcare and increasing the payments of clinical services and make doctors more professional.

All (non-)stakeholders may play their part [1-7]. Though the tragedies mentioned above were hate crimes against healthcare givers, tolerating against one group often leads to tolerance of violence other members of society or even vulnerable parties associated with healthcare workers, such as the children in kindergarten in a town in Jiangsu, women working on night shifts, etc. We and our government led by President Xi Jin-Ping would like to play our part to counter the status quo, joining the millions of doctors, nurses, researchers, educators and their allies of who will push the campaign against $\mathrm{AHcV}$ forward.

\section{References}

1. Sacks CA, Malina D, Morrissey S, Campion EW, Hamel MB, et al. (2016) In the wake of Orlando - taking steps against gun violence. N Engl J Med 375: e19.

2. Ping XJ (2016) Give the priority to the health care of the people. Xinhua News (accessed Aug 20, 2016).

3. Tucker JD, Cheng Y, Wong B, Gong N, Nie JB, et al. (2015) PatientPhysician Trust Project Team. Patient-physician mistrust and violence against physicians in Guangdong Province, China: a qualitative study. BMJ Open 5: e008221.

4. Wu LX, Qi L, Li Y (2016) Challenges faced by young Chinese doctors. Lancet 387: 1617.

5. National Health and Family Planning Commission of China (2015) The instructions on pilot implementation of specialist standardization training.

6. Zhang ZY, Li CL, Wang WY, Zhang Y (2016) China' s precision medicine should aim for innovation. Human Genet Embryol 6: el13

7. (2016) South China doctor killed by former patient. CRJ English. (accessed: Aug 12, 2016). 